\title{
A NOTE ON TRANSLITERATION
}

Transliteration from Slavic to Latin script is always a challenge, particularly where proper nouns are concerned. Throughout this book I have attempted to follow the guidelines of the US Library of Congress wherever possible. However, for place names the American Association of Geographers has its own conventions, and in most places I have followed those. (Thus: Ob River instead of Ob.) Finally, if a place or person has been mentioned frequently in the Western media, then I follow the spelling used in the media. (Thus: Mikhelson instead of Mikhel'son.) Unfortunately, the result is a running series of compromises, which will make no one entirely satisfied. 



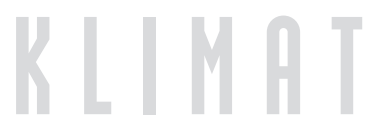




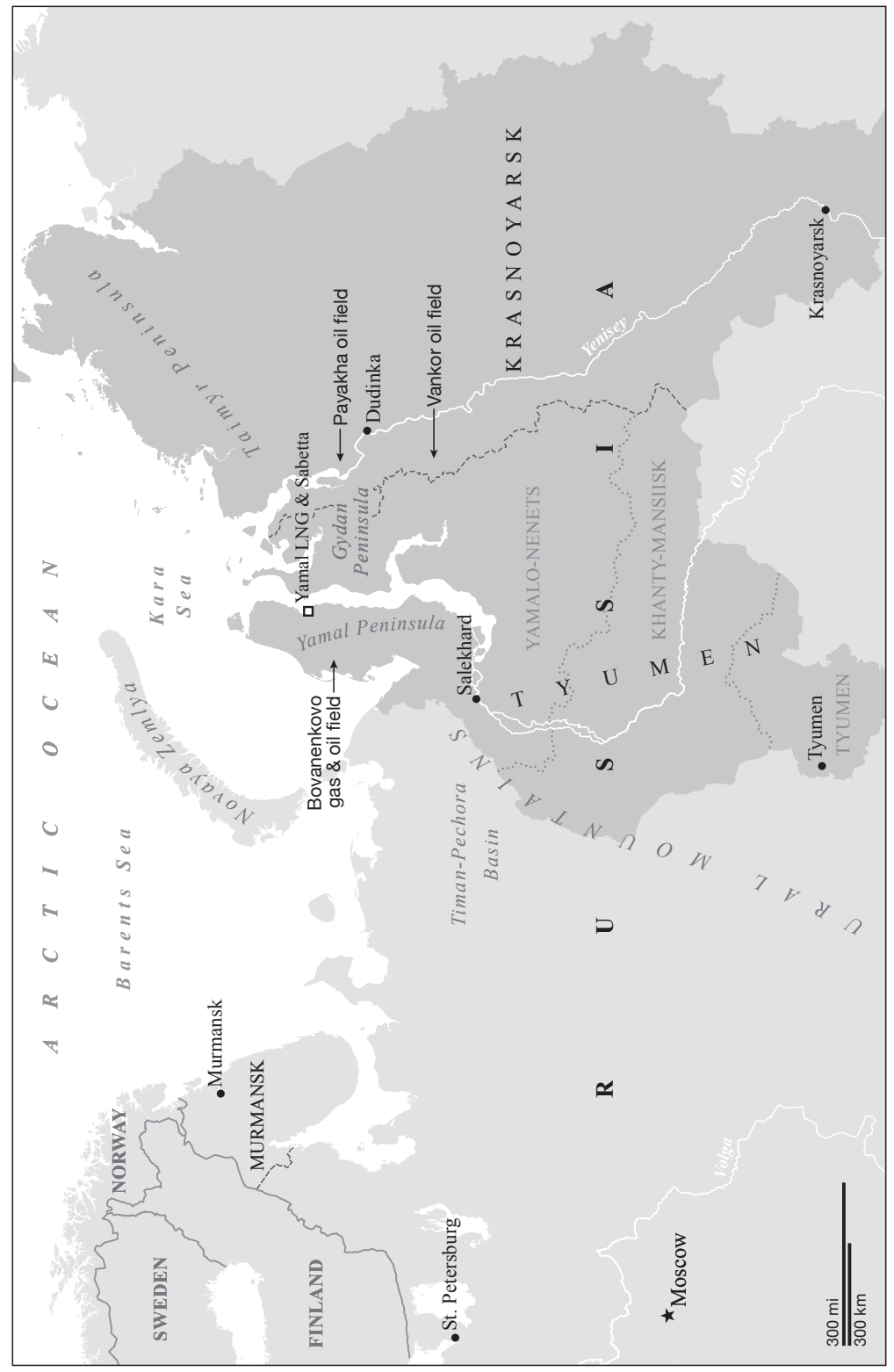




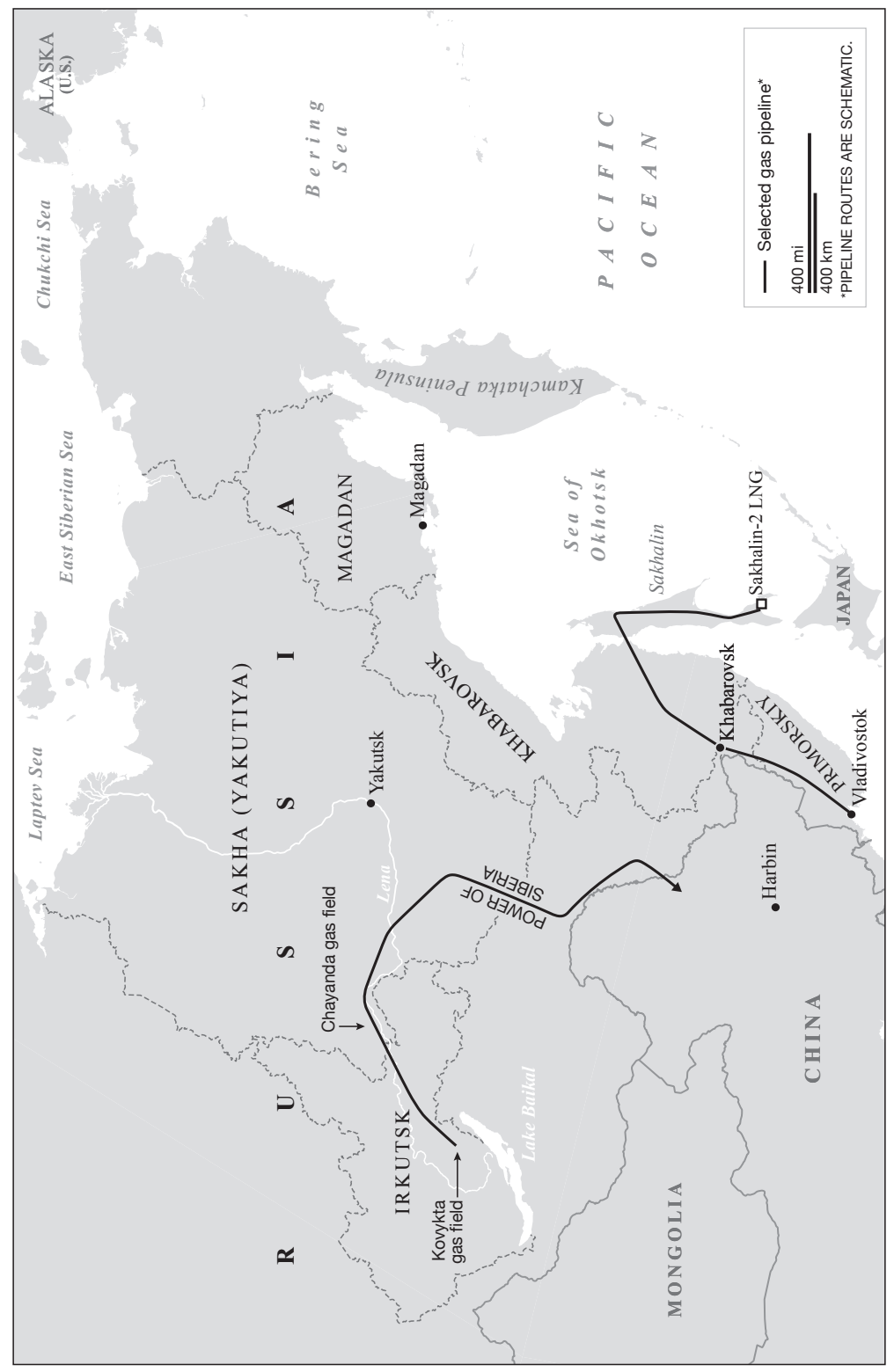


